\title{
Popper e a ética médica: a proposta de popper de um novo ethos para a medicina
}

\author{
Popper and medical ethics: the proposal for a new ethos \\ for medicine
}

\author{
Prof $^{\text {a }}$. Dra. Elizabeth \\ Assis Dias \\ Programa de Pós-graduação \\ em Filosofia e do Curso de \\ graduação em Filosofia da \\ Universidade Federal do Pará \\ (UFPA) \\ e-mail: 리ias@ufpa.br

\section{ORCID} \\ https://orcid.org/0000-0003- \\ $\underline{0951-6313}$
}

Recebido em: 24/03/2021

Aceito em: 18/10/2021

\section{Resumo}

O objetivo do presente trabalho é analisar a proposta de Popper de uma nova ética para a medicina, que tem como pressuposto o erro médico, suas consequências e responsabilidades, e também, evidenciar novas atitudes a serem cultivadas pelos médicos como formas de preveni-los. Nesse sentido o filósofo propõe o diálogo, a discussão crítica e o trabalho em equipe. Mas, como ele aborda a questão da ética médica de uma forma mais ampla, estabelecendo certos vínculos entre ela e a concepção de ciência sob a qual os médicos foram formados, pretendemos mostrar que para que eles venham a assumir uma atitude ética e responsável face aos erros faz-se necessário que superem uma antiga forma de conceber a ciência, que valoriza a certeza e a infalibilidade, que está incrustada em suas mentes e faz com que se vejam como uma autoridade infalível em sua especialidade.

Palavras chave: ciência, falibilismo, erro, ética, responsabilidade.

\section{Abstract}

The aim of the present paper is to analyze Popper's proposal for a new ethics for medicine, which presupposes medical error, its consequences and responsibilities and also, to show new attitudes to be cultivated by doctors as ways to prevent them. In this sense, the philosopher proposes, dialogue, critical discussion and teamwork. But, as he addresses the issue of medical ethics in a broader way, establishing certain links between it and the conception of science under which doctors were trained, we intend to show that for them to come to assume an ethical and responsible attitude towards the errors it is necessary to overcome an old way of conceiving science, which values certainty and infallibility, which is embedded in their minds, and makes them see themselves as an infallible authority in their specialty.

Key words: science, fallibilism, error, ethics, responsability 


\section{Introdução}

A preocupação com um ethos para a ciência tem se mostrado mais evidente, na contemporaneidade, devido ao próprio avanço das pesquisas cientificas e o aumento das aplicações práticas dos conhecimentos produzidos. Esta preocupação se apresenta no pensamento de vários filósofos, que têm se voltado para questões sobre os fins das produções cientificas e de suas aplicações, sobre os perigos dos seus usos indevidos, sobre os valores com os quais os cientistas estão comprometidos, como também, para a questão da responsabilidade ética dos cientistas com relação aos resultados de suas pesquisas e com relação ao exercício de sua própria prática, considerando-se os problemas éticos que ela envolve. Popper, em alguns de seus escritos, refletiu sobre essas questões e procurou delinear sua proposta de uma "nova 'ética profissional' para os cientistas e médicos" (POPPER, 1987a, p.107). Mas, uma tal ética não deve ser entendida como "uma espécie de moral da corporação" ou como um "código de conduta" para reger o comportamento dos médicos e cientistas no exercício de sua prática.

Alguns autores procuram caracterizar este tipo de preocupação popperiana como a defesa da necessidade de uma "ética aplicada" a ciência (FERRIOL, 2006). Entretanto, essa ética não deve ser vista como uma disciplina que tendo por base princípios éticos gerais, pretende aplicá-los ao âmbito de casos concretos, seguindo o modo de operar do silogismo dedutivo (CORTINA, 2008). Trata-se de olhar a ética a partir de um "marco de aplicação" e de se delinear valores, princípios e procedimentos, que os sujeitos envolvidos no âmbito desse contexto devem levar em consideração para tomar suas decisões. São eles que devem pesar as consequências de suas decisões em cada situação concreta e fazer suas escolhas (CORTINA, 2008).

A nova ética que Popper propõe para a medicina tem essa natureza de uma "ética aplicada", na medida em que pretende definir alguns princípios para nortear a prática médica tendo em vista a responsabilidade ética dos médicos para com seus pacientes. O filósofo considera que certas atitudes, no exercício da profissão, são determinadas pela ética que a norteia, ou seja, por princípios que definem se determinadas ações são corretas ou incorretas. Esses princípios influenciam os protocolos médicos, as regras de conduta que devem ter com relação aos colegas e com relação aos pacientes (POPPER, 2014).

Com efeito, as reflexões éticas de Popper, no âmbito da medicina, tem como pressuposto o erro médico, suas consequências e a responsabilidade face aos mesmos e pretende evidenciar novas atitudes para enfrentá-los e preveni-los. Mas, para tal, não se restringe apenas a definir certos princípios para a prática médica, pois aborda a questão de uma forma mais ampla na medida em que aponta um certo vínculo entre a ética de uma profissão, a concepção de ciência e de método que esses profissionais assimilaram no decorrer de sua formação. Assim, para que venham a assumir uma atitude responsável e ética face aos seus erros, faz-se necessário que superem a antiga forma de ver a ciência, que valoriza a certeza e a infalibilidade, que está incrustada em suas mentes, e faz com que se vejam como um expert, uma autoridade infalível em sua especialidade. A percepção de que a ciência é falível e que avança eliminando os erros e buscando teorias melhores pode possibilitar que os médicos assumam novas atitudes faces aos erros e procurem formas de se acautelar com relação a eles tendo em vista que a responsabilidade maior é com o bem do paciente. Diríamos que Popper pretende definir um novo ethos para a medicina, na medida que em sua proposta implica em mudar antigos costumes, hábitos, valores que se encontram firmemente arraigados na prática médica, como também, a própria forma de conceber a ciência. Deste modo, só podemos compreender sua proposta se considerarmos certos pressupostos epistemológicos que estão vinculados a ela.

Este trabalho tem a pretensão de evidenciar os fundamentos epistemológicos que norteiam o novo ethos que Popper propõe para a medicina, como também, analisar sua proposta de uma ética alicerçada na ideia de erro e de responsabilidade dos médicos com relação aos mesmos.

Nossa abordagem terá como fundamento alguns escritos de Popper sobre a sua teoria da ciência, como A Lógica da pesquisa cientifica (1972), Realismo e Objetivo da ciência (1987b) e Conjecturas e refutações (1982), nos quais nos apresenta sua concepção de ciência como conhecimento falível e o progresso como superação de erros, e também, seus escritos acerca de questões éticas inerentes a ciência, como: "A responsabilidade moral do cientista" "La actitud crítica em medicina. La necessid de uma nueva ética" (2014) e "Tolerância e 
responsabilidade intelectual" (1987a), nos quais apresenta suas reflexões sobre uma "ética aplicada" à ciência e propõe uma "nova ética profissional para a medicina".

\section{As bases epistemológicas do novo ethos}

A medicina é considerada pelos gregos como uma arte ou téchne. Tal termo se refere ao domínio de certas habilidades para fazer algo específico. Nesse sentido, tanto o médico, quanto o arquiteto, o agrimensor, o escultor dominam uma certa téchne. Mas esta não se resume a um mero fazer ou produzir, ou seja, a uma simples atividade prática, pois é orientada por um certo conhecimento prévio da coisa a ser feita.

Aristóteles, na Metafisica, muito embora considere que os homens adquirem a arte, como também, a ciência, por meio da experiência procura diferenciá-las. A primeira conhece apenas o particular, o contingente, ao passo que a segunda, o universal, que decorre de várias noções experimentadas de objetos semelhantes. Ilustra essa diferença através de um exemplo da arte médica. Assim, ter a noção de que um determinado medicamento faz bem para Sócrates e Kalias, que sofrem de uma determinada doença, diz respeito à experiência. E conhecer universalmente, isto é, que a todos os indivíduos de uma mesma classe, acometidos de uma mesma enfermidade, um determinado medicamento lhes fará bem, é próprio da arte. Assim, quem pratica a arte médica tem o domínio de conhecimentos que o habilitam a julgar de forma universal e não apenas a experiência no trato de casos particulares. Fica evidente que conhecer e ter discernimento são próprios da arte e não da experiência, pois ela sabe o porquê e a causa. O conhecimento pela causa implica em conhecer pelo universal, ou seja, pelo conceito, ao passo que a experiência tem apenas a noção do quê, ou seja, do puro dado. O médico ao conhecer a natureza da enfermidade e do medicamento, conhece o nexo causal entre eles e, assim, a causa da recuperação da saúde, ou seja, da cura da doença (ARISTÓTELES, 2002). Mas, o médico no domínio de sua arte não pode conhecer apenas o universal, a teoria, sem a experiência, pois, sem conhecer o particular que aquela contém, cometerá erros no tratamento, uma vez que o objeto da cura é o particular. Diz ele: "O médico não cura o homem a não ser acidentalmente, mas cura Cálias ou Sócrates ou qualquer outro indivíduo que leva um nome como eles, ao qual ocorra ser homem” (ARISTÓTELES, 2002).

Popper considera também, a medicina como uma "arte" ou "técnica", que pressupõe o conhecimento teórico, mas tem um caráter distinto das ciências teóricas ou puras. Trata-se de uma ciência aplicada (POPPER, 1982). As ciências puras ou teóricas têm por interesse leis universais e em submetê-las a testes visando eliminar as falsas, já que na concepção falseacionista do filósofo, não é possível determinar se são verdadeiras. As ciências aplicadas, por sua vez, possuem um interesse diferente, o prognóstico. Elas tomam as teorias ou leis universais como meios para esse fim (POPPER, 1974b). Assim, no caso da medicina, o médico diante de certos sintomas relatados pelo doente e tendo certas teorias como assentes, poderá fazer um diagnóstico e indicar um tratamento adequado, que leve ao restabelecimento de sua saúde. A escolha do tratamento cabe ao profissional da saúde, mas, ele não pode ignorar as teorias científicas que o respaldam, bem como certas particularidades e especificidades do doente, pois, como bem chamou atenção Aristóteles, é o individuo que ele trata.

É importante observar que as ciências aplicadas, para a consecução de seus fins, devem se apoiar em teorias que foram obtidas tendo por base rigorosos procedimentos metodológicos, que atestaram sua qualidade, ou seja, foram submetidas a testes severos que a corroboraram.

Assim, a decisão de um médico ao prescrever determinado tratamento a um doente, não pode estar respaldada em suas convicções pessoais, em sua crença subjetiva, mas sim em um conhecimento objetivo, que é produto de um procedimento metodológico. Esse conhecimento passou pelo crivo da critica intersubjetiva, ou seja, foi avaliado por uma comunidade científica especializada, que revisou todas as etapas do método e o submeteu a provas, de modo a identificar e eliminar os erros, ou seja, as teorias falsas (POPPER, 1974b).

Mas, mesmo a teoria que passou por testes pormenorizados e severos que a corroboraram não pode ser vista como uma verdade ad eternum. Trata-se de uma "verdade provisória", ou melhor, de uma explicação provisória, 
pois testes subsequentes aos quais a teoria venha a ser submetida poderão identificar erros, que se constituirão em motivos para rejeitá-la (POPPER,1972). As teorias científicas são assim, falíveis e sujeitas a erros. Tem o caráter de hipóteses ou conjecturas, que são susceptíveis de critica e que podem vir a ser substituídas por outras melhores. A noção de Ciência com "C" maiúsculo, ou seja, como uma autoridade, que tem em seu âmbito o conhecimento certo e demonstrável é equivocada. Não há certezas absolutas na ciência (POPPER, 1972).

Deste modo, o cientista e o próprio médico não podem pensar que têm a "posse do conhecimento certo" ou da "verdade irrefutável" e que tal posse os torna uma autoridade infalível. Conforme comenta Popper: "a ciência não tem autoridade. Não é o produto mágico do dado, dos dados, das observações. Não é um evangelho da verdade" (1987b, p. 269). O filósofo contrapõe-se assim, a concepção positivista de ciência, alicerçada em fatos e verificada por eles. E que, no decorrer dos séculos, foi vista como o ideal de ciência. Tendo por base sua concepção falseacionista e falibilista critica esse ideal, que também, foi aplicado à ciência médica.

$\mathrm{Na}$ Medicina, como em outras profissões, se comete erros e estes geram consequências que poderão ser trágicas, na medida em que vidas humanas poderão vir a ser destruídas. E estes erros são de diferentes naturezas: em decorrência de teorias duvidosas que o médico toma como referência para prescrever um tratamento; diagnóstico equivocado; indicação de medicamentos inócuos para uma determinada enfermidade; efeitos colaterais desconhecidos ou não previstos de um medicamento, que ele ignorava; falhas ao realizar determinados procedimentos, como por exemplo, uma cirurgia, etc.

Entretanto, acentuam Gorowitz e Macintyre, há uma certa resistência dos médicos para fazerem registros completos e sistemáticos de seus erros, tal atitude se deve talvez, por acreditarem que o erro é fruto da ignorância ou incapacidade deles e de seus colegas (GOROWITZ; MACINTYRE, 1976). Mas, se torna cada vez mais evidente que qualquer autoridade científica pode cometer erros. Inclusive, grandes cientistas como Einstein, por exemplo, cometeram erros. A este respeito, Born relata que Einstein foi partidário do programa de investigação que buscava uma teoria do campo unificado, que foi abandonado, posteriormente, quando Yukawa propôs a teoria das forças nucleares (POPPER, 2014).

É importante que se tenha sempre em vista que a ciência é um produto do esforço humano de conhecer, representa a nossa esperança de nós libertarmos da ignorância e das limitações de nossas mentes, assim, como da superstição e do fanatismo (POPPER, 1987b). Contudo, enquanto produto humano, está marcada pelos fracassos e limitações humanas. A ciência é falível, porque é produzida por seres humanos falíveis e passíveis de erros. "Errar é humano", já diz o ditado popular. E para o avanço do conhecimento é importante que esses erros sejam identificados e superados.

No caso da medicina, o registro dos erros se mostra importante para o próprio avanço da prática médica, pois se os médicos querem descobrir por que os erros ocorrem e como evitá-los, precisam registrá-los, analisá-los, discuti-los criticamente. Mas, para que assumam tal posição face aos erros faz-se necessário que superem certas atitudes e ideias profundamente arraigadas na prática da profissão, que decorrem da concepção que tem acerca da natureza dos conhecimentos que detém e dos métodos utilizados para adquiri-los, fruto da própria formação médica que receberam, baseada em uma concepção empírico-indutiva do conhecimento. E como esta concepção de conhecimento e método acaba por influenciar a ética de uma profissão, consequentemente, precisam também, superá-la.

Tal ética está calcada em uma concepção de conhecimento tido como certo, seguro, verificado empiricamente, que progride por acumulação de fatos e que pode concentra-se na mente de uma pessoa, ou seja, ela tem sua posse, é possuidora de uma verdade inquestionável. Essas ideias, adverte Popper, criam as condições favoráveis para o surgimento de autoridades, que se veem como portadoras de conhecimentos infalíveis. Ser uma autoridade torna-se, assim, o ideal da profissão (POPPER, 2014). Os médicos, que foram formados sob esta tradição, acabam assimilando tal ideal, na medida em que se julgam um expert, ou seja, detentores de todos os conhecimentos e habilidades necessários para a prática de seu oficio, acreditam que são infalíveis. E quando falham seus erros precisam ser ocultados para não comprometer a sua autoridade. É importante notar que no Brasil a tendência ainda é a de esconder o erro ao invés de vê-lo com parte do trabalho desenvolvido pelo médico (BRAGA, 2018). 
Assim, essa ética, que ao invés de identificar os erros e buscar meios de corrigi-los, os oculta, conduz a uma ideia de autoridade, desprovida de honestidade e de probidade intelectual (POPPER, 2014). É essa "autoridade" advinda de um saber inquestionável, que também, dá ao médico, por exemplo, o poder de decidir que tratamento prescrever ao doente, sem ao menos duvidar de sua eficácia.

Hoje alguns médicos já demonstram ter consciência das limitações e da falibilidade dos conhecimentos que possuem e, considerando os avanços da ciência, procuram constantemente se atualizar, incorporando novos conhecimentos a sua formação e mudando suas condutas clínicas face a novas evidências (LEMOS, 2021). Mas, isto não acontece, em geral, com os códigos de ética médica, pois os seus legisladores não procuram adaptar tais códigos aos avanços da ciência e da própria tecnologia (CRAVEN-BARTLE, 2003).

Uma outra atitude a ser superada, influenciada pela anterior, decorre de uma educação que valoriza a acumulação de conhecimento e sua memorização. O estudante de medicina, assim como de outras áreas, desde sua formação é incentivado a assimilar, mecanicamente, os conhecimentos que lhes são repassados e seu desempenho nos exames é avaliado em termos dessa memorização. Sendo penalizado por seus erros. Desta forma, é educado para ver o erro como algo negativo, fruto de sua ignorância e que precisa ser encoberto. Essa atitude negativa face ao erro o impossibilita de aprender com seus próprios erros e superá-los (POPPER, 2014).

A ciência é vista por Popper, como uma das poucas atividades humanas, na qual os erros devem ser submetidos a critica de forma sistemática e corrigidos (POPPER, 1982). Por isso, se pode dizer que no âmbito da ciência se aprende com os erros. E à medida que ocorre tal aprendizagem o conhecimento progride. $\mathrm{O}$ progresso científico é assim concebido como a substituição de velhas teorias, que apresentaram falhas ou erros na solução de determinados problemas, por outras melhores, que posteriormente, poderão vir apresentar falhas ao se depararem com novas situações, não previstas, e que irão indicar que a teoria precisa ser revista. Não há, portanto, na ciência, conhecimentos absolutamente certos e inquestionáveis.

Em medicina, assim como em outras áreas do conhecimento, deve-se duvidar do que parecer ser óbvio, evidente por si mesmo e até mesmo do que é reputado como verdadeiro. O que parece certo, indubitável, pode vir a se mostrar falso. Tal situação pode ser ilustrada com certos medicamentos que foram reputados como sendo eficazes para a cura da covid-19, mas que, com os estudos posteriores, foi constatada sua ineficácia.

Podem existir, assim, controvérsias com relação à eficácia de determinados tratamentos indicados aos pacientes e quando não há consenso, os médicos devem ter uma certa prudência ao prescrevê-los, principalmente, quando a ciência ainda não chegou a resultados bem corroborados. A existência de divergência quanto a esses resultados, denota que há lacunas, falhas ou erros, que precisam ser corrigidos ou que as teorias são falsas e precisam ser abandonadas. Para tal, a avaliação critica e a retroalimentação, ou seja, o feedback, se mostra importante. E a melhor atitude a tomar, ao invés de se defender dogmaticamente certas verdades, é ouvir a opinião de outros, discutir com eles. Manter assim, a mente aberta e procurar aprender com os que sustentam uma posição diferente. Pois, como diz Popper: o outro pode ter razão e eu posso está equivocado. Mas, tal posição não significa que a verdade seja relativa, pois ambos podem está equivocados (POPPER, 2014). Assim, ao se discutir racionalmente certos assuntos, é possível se corrigir os erros e se aproximar da verdade ou se ter uma atuação melhor, no caso da prática médica.

Os médicos poderão, portanto, melhorar sua atuação, se cultivarem uma atitude que lhes possibilitem discutir criticamente os erros, tendo em vista a verdade. Esta deve ser a meta da ciência. O que define o caráter da ciência e do próprio cientista "é a persistente e arrojada procura critica da verdade" (POPPER, 1972, p.308). Entretanto, tal ideal é difícil de ser alcançado, mas com a adoção de uma atitude que valorize o reconhecimento dos erros e sua eliminação é possível se aproximar da verdade e deste modo evitar erros futuros (POPPER, 2014).

Por outro lado, é fundamental que o médico tenha consciência de que a ciência avança rapidamente, que teorias consideradas como verdadeiras hoje, posteriormente, podem vir a se mostrar falsas, pois surgiram novos fatos que ela se mostrou incapaz de explicar. A mesma situação se aplica aos medicamentos reputados 
como eficazes para o tratamento de determinados enfermidades, eles podem vir a se mostrar inócuos ou ineficazes. Esse progresso da ciência requer do médico, uma atualização constante. Então, ele não pode em nome de sua suposta autoridade se arraigar a teorias obsoletas e prescrever tratamentos que venham por em risco a vida do doente.

Mas, ao ressaltarmos que a medicina é falível e sujeita a erros, como qualquer outro conhecimento humano, não queremos dizer que ela não tem um valor ou que não devemos confiar nos médicos. Não se trata de negar o valor da medicina, enquanto ciência aplicada. Pelo contrário, nossa pretensão é mostrar que ela pode se mostrar mais eficaz, se certas atitudes e posições forem avaliadas e criticadas e se a prática médica for repensada, considerando-se as questões epistemológicas apontadas, que se apresentam em seu âmbito.

O valor da medicina não está apenas na cura da enfermidade, ou seja, na prescrição do tratamento correto para o restabelecimento da saúde do doente, mas também, na busca de tratamentos mais eficazes para essa cura, e na ausência desses, na busca de maneiras de se aliviar o sofrimento humano. Nesse sentido, o médico deve ser um pesquisador, alguém que está sempre em busca da verdade. Deve também, ter consciência da falibilidade dos conhecimentos que dispõe e que precisa manter uma atitude critica face aos mesmos; e compreender que há certas enfermidades, ou certos males que afligem os doentes, que contrariam suas hipóteses, e que precisam ser estudados e analisados à luz de novas hipóteses. Enfim, deve saber que a ciência está sempre em progresso e o quanto é perigoso para a saúde dos enfermos se arraigar a teorias duvidosas ou ultrapassadas.

E quando se trata de preservação da vida do doente, do seu bem-estar, ou do alívio de seu sofrimento há outras questões envolvidas, além das epistemológicas. Estas dizem respeito à ética, mais precisamente as responsabilidades dos médicos e certas atitudes que devem ser cultivadas face aos conhecimentos que possuem e aos seus erros.

\section{A nova ética proposta por popper:}

As reflexões de Popper, em termos de uma nova ética para a medicina se apresentam, primeiramente, em alguns escritos nos quais ele trata de questões relativas à ética na ciência, como "Tolerância e responsabilidade intelectual" (1987a) e "A responsabilidade moral do cientista" (1999). Posteriormente, no artigo "La actitude crítica em medicina: la necessidade de una nueva ética" (2014) retoma algumas ideias presentes nos escritos anteriores e defende uma nova ética que leve em consideração os erros médicos.

Popper considera relevante a discussão de questões éticas relativas à ciência, principalmente as que dizem respeito às responsabilidades éticas dos cientistas, porque na atualidade grande parte dos conhecimentos científicos tornou-se potencialmente aplicável (POPPER, 1999).

As ciências aplicadas, como a medicina, necessitam de uma ética para orientá-las nas decisões a serem tomadas quando enfrentam questões que envolvem a vida e o bem do ser humano. Tal ética não deve ser entendida como um código de conduta, pautado sobre bases cientificas, que tenha a pretensão de estabelecer o que os cientistas e médicos devem fazer em determinadas situações. Uma ética entendida dessa forma seria um contrassenso, na medida em que fere a autonomia dos indivíduos e os exime de suas responsabilidades (POPPER, 1974a).

Com efeito, é importante lembrar que hoje já existem campos específicos do conhecimento que se dedicam ao exame de questões éticas relacionadas à área médica, que vem ganhando relevância e ampliando o âmbito das temáticas, objeto de suas investigações, como a deontologia médica que, inicialmente, procurava dar conta de questões referentes aos deveres e direitos médicos relativos ao exercício da profissão e, posteriormente, alargou seus horizontes passando a tratar de temas éticos voltados para a área das ciências biológicas (NEVES, 2006). E a bioética, cujo surgimento está relacionado à ideia de orientar a utilização dos novos recursos tecnológicos, advindos do avanço da ciência, nas áreas médicas e biológicas, considerando os desafios e riscos para a humanidade. Nesta sua tarefa, procurava estabelecer certos vínculos entre os conhecimentos 
científicos, as humanidades e a ética. Seu campo de preocupação e atuação tem se ampliado de modo a dar conta de questões para além das ações biomédicas (NEVES, 2006).

As reflexões de Popper, muito embora expressem algumas preocupações comuns a esses campos de estudos, são vistas de uma perspectiva mais abrangente, própria à filosofia e trazem o traço do seu racionalismo crítico, que se configura em uma atitude prática que nos dispõe a ouvir os argumentos críticos dos outros, considerando que podemos estar errados e o outro certo (POPPER, 1974b). E é essa atitude critica que ele pretende trazer para o âmbito da ética médica ao voltar-se para o erro médico. Sua reflexão se mostra bastante atual, pois ainda hoje, a questão do erro médico é objeto de preocupação da categoria médica e muitas vezes tem sido tratada da perspectiva administrativa, pelos hospitais e Conselhos de Medicina, ou então, na esfera jurídica, considerando-se os danos causados à integridade física do paciente e não de forma educativa.

A abordagem crítica popperiana, do fazer dos cientistas e médicos não separa as questões epistemológicas das questões éticas, pois conforme mostramos anteriormente, a concepção que se tem da ciência e dos seus procedimentos metodológicos influencia a forma de se conceber a ética de uma profissão. Deste modo, sua análise possibilita que os médicos compreendam que as questões éticas atinentes ao exercício da profissão não podem ser tratadas de forma desvinculada das questões postas pelo próprio avanço do conhecimento.

Um exemplo de uma situação, que denota essas imbricações, diz respeito às discussões recentes entre médicos e cientistas sobre tratamentos precoces e duvidosos a serem indicados aos pacientes acometidos de COVID-19. Face a tais debates o presidente do Conselho Federal de Medicina (CRM), defendeu o princípio ético da autonomia do médico para tratar seu paciente da forma que julgar mais conveniente (RIBEIRO, 2021). Sua posição é baseada apenas no código de ética médica, sem levar em consideração os avanços das pesquisas sobre o assunto. Tal ponto de vista gerou manifestações de diferentes setores das sociedades científicas e médicas, que questionaram os limites da autonomia médica (TESSLER E TÓFOLI, 2021). Os diferentes autores, em suas objeções, evocavam o próprio valor da medicina de zelar pela saúde dos pacientes e a necessidade da prática médica estar respaldada nos avanços da ciência (RAMOS FILHO ET AL., 2021), e além do mais, enfatizaram certos preceitos éticos que norteiam a prática médica (LEMOS, 2021). Observa-se assim, que questões éticas, como as relacionadas à autonomia médica, e o avanço da ciência estão relacionadas e que tal autonomia tem limitações, pois o médico não pode tomá-la como fundamento absoluto para suas decisões. Por conseguinte, em nome dela, não pode prejudicar o doente, ou seja, não pode lhe imputar tratamentos que não estejam respaldados pela ciência e que venham a comprometer sua saúde.

A ética que Popper preconiza está fundada, justamente, na ideia de autonomia, que ele tomou emprestada de Kant, mas que deu a ela uma interpretação própria, na medida em que procura dar ênfase a responsabilidade pelas consequências de uma ação como exigência moral (DIAS, 2021). Entende que o sujeito autônomo deve decidir por si mesmo, ou seja, é livre para fazer suas escolhas, ou melhor, para decidir como deve agir. Nesse sentido, não deve aceitar, cegamente, o que lhe ordena uma autoridade, por mais elevada que esta seja, no que diz respeito a questões éticas. Face uma ordem emanada de uma autoridade a decisão de obedecê-la cabe ao sujeito, ou seja, a responsabilidade é sua, ao julgar se tal ordem é moralmente aceitável ou não (POPPER, 1982). O conceito de autonomia deixa transparecer a noção de liberdade, como também a de responsabilidade, na medida em que implica em reconhecer que o sujeito é livre para fazer sua escolha, ou seja, que é capaz de decidir por si mesmo e, por conseguinte, é responsável por tal decisão. Diz Popper: "Contudo, a não ser que sejamos impedidos fisicamente de fazer uma escolha, a responsabilidade será nossa. A decisão de obedecer a uma ordem, de aceitar uma autoridade, é uma decisão que nos pertence" (POPPER, 1982, p. 208).

A ética popperiana pressupõe e requer a responsabilidade do sujeito por suas decisões. Trata-se, conforme a denominou Ferriol, de uma ética da responsabilidade (2006), que leva em consideração as consequências de uma ação. No caso da medicina, se um médico decide, prescrever um tratamento duvidoso a um doente, recairá sobre ele as consequências de sua decisão, ou seja, ele é responsável pelos males ou sofrimentos que venha a causar ao enfermo. E, por mais que uma autoridade superior a ele, lhe tenha recomendado tal tratamento, se não foi coagido a fazê-lo, a responsabilidade pelas consequências de tal ato, será sua. É importante 
ressaltar que tal decisão não deve estar norteada apenas pela ideia de bem, no sentido de não causar prejuízos ao doente, mas também, por teorias corroboradas pela avaliação dos pares, pois como mostramos anteriormente, as ciências aplicadas precisam das teorias para seus prognósticos.

Essa ética da responsabilidade dos cientistas, que Popper esboça em seus escritos, em um contexto em que ainda predominavam as preocupações com os fundamentos lógico-metodológicos da ciência, evidencia que os problemas relativos às aplicações da ciência, seus fins, interesses e consequências para a humanidade não lhes eram indiferentes. Encontramos essas preocupações em vários filósofos que o sucederam e se voltaram para as questões éticas postas pela tecnociencia. Mas, vale salientar, que as reflexões de Popper, que trazem para o centro de sua ética, a responsabilidade do cientista para com a humanidade, de certa forma antecipam ideias que foram desenvolvidas por outros filósofos. Nesse sentido, é importante lembrar as reflexões de Hans Jones, em sua obra, O principio da responsabilidade: ensaios de uma ética para a civilização tecnológica (2006), que partindo do pressuposto que a responsabilidade advém da liberdade, propõe um "princípio da responsabilidade", no qual expressa sua preocupação com as futuras gerações tendo em vista os avanços técnico-científicos. Tal princípio é expresso nos seguintes termos: "Aja de modo a que os efeitos da tua ação sejam compatíveis com a permanência de uma autêntica vida humana sobre a Terra" (JONAS, 2006, p. 47). Sua pretensão é propor uma ética para a civilização tecnológica. Entende que a ética deve impor limites a atuação dos cientistas, principalmente se o avanço técnico-científico vier a ameaçar a vida no planeta e provocar consequências negativas. Encontramos também, no pensamento do filósofo alemão, reflexões sobre a pesquisa médica com seres humanos. Observa-se que recorre, em suas análises, a duas noções da tradição filosófica, que são valorizadas por Popper, em sua proposta de uma ética para a ciência, a liberdade e a responsabilidade. Em sua obra, Técnica, Medicina e Ética (2013), Hans Jonas discute vários problemas éticos que decorrem de pesquisas envolvendo seres humanos, à luz dessas noções. Entende, tal como Popper, que a liberdade requer responsabilidade, mas que ao se praticar uma ação deve-se levar em consideração as consequências, ou seja, os possíveis danos que se possa causar de modo a se evitar que certas situações que envolvem riscos para a humanidade não se concretizem. Sua pretensão é de impor "barreiras de responsabilidade" de modo a possibilitar uma nova consciência (JONAS, 2013, p. 112). As suas reflexões acerca dessas questões vão além das preocupações de Popper, pois estão voltadas para as pesquisas nas áreas médicas e os novos desafios que enfrentam decorrentes dos avanços da tecnociência e dos experimentos com seres humanos.

A questão da responsabilidade ética dos cientistas e, em particular, dos médicos é analisada por Popper, tendo por base alguns compromissos expressos no "Juramento de Hipócrates", que ele vê não como um juramento de licenciatura, mas sim como de um aprendiz da profissão médica (POPPER, 1999). A ideia de concebê-lo como um "juramento de aprendiz" visa possibilitar aos estudantes de uma determinada especialidade, a discussão de questões relacionadas à ética desde o inicio de sua formação, de modo que tomem consciência das responsabilidades que terão que assumir quando se tornarem cientistas criativos (POPPER, 1999).

Tal Juramento é constituído de três partes: a primeira, expressa o compromisso do discípulo (aprendiz) para com o mestre, no sentido de reconhecer sua obrigação pessoal para com ele; a segunda, diz respeito a sua promessa de perpetuar a sua arte e preservar seus padrões elevados, bem como transmiti-los as novas gerações e a terceira, trata do seu compromisso de ajudar os que sofrem e guardar silêncio sobre o que venha a tomar conhecimento no exercício de sua prática (POPPER, 1999).

A ideia de Popper é elaborar uma nova versão deste juramento de modo a adequá-lo a situação presente e, assim, chamar a atenção para as questões éticas, que ele envolve, como também, possibilitar que elas sejam discutidas criticamente pelo aprendiz da ciência médica. Em sua proposta procura não apenas inverter a ordem dos compromissos do juramento, mas também, generalizá-lo, de modo a estendê-lo a outras profissões.

Na sua versão renovada do "Juramento de Hipócrates", Popper coloca em primeiro lugar, a responsabilidade ética. Nesse sentido, o dever de todo profissional e estudante de uma determinada especialidade é contribuir para o crescimento do conhecimento, para tal deve participar na busca da verdade ou de melhores aproximações à mesma. Este primeiro dever constitui o cerne da relação entre o trabalho do cientista $\mathrm{e}$ a ética, pois a verdade que eles devem buscar não constitui apenas um valor epistêmico, mas também, um 
valor ético, na medida em que o conhecimento pode, potencialmente, ser aplicado. E este compromisso com a busca da verdade pressupõe também, que os conhecimentos que possuem são limitados e falíveis e a sua ignorância é ilimitada (POPPER, 1999). O segundo elemento desse juramento, diz respeito ao estudante. Este, enquanto participante de uma comunidade cientifica e de uma tradição, deve se comprometer a respeitar a todos que tenham contribuído para a busca da verdade, como também, deve ser leal aos seus mestres que compartilharam com ele seus conhecimentos. Mas, ao mesmo tempo, deve ter o compromisso de ser crítico, seja com relação aos outros, inclusive seus mestres, como também, em relação a si próprio. E acima de tudo, tem o dever de evitar a arrogância intelectual, como também, não se deixar levar por modas (POPPER, 1999). O terceiro elemento, diz respeito à lealdade suprema. Esta deve ser, prioritariamente, à humanidade, do mesmo modo que o médico deve lealdade suprema a seus pacientes. Nesse sentido, ele tem o dever de não prejudicá-los. Assim, o aprendiz de uma profissão, os cientistas, e os médicos devem ter consciência de que certas pesquisas, assim como, alguns tratamentos prescritos aos doentes, produzem consequências que podem afetar a vida de muitas pessoas e por isto, devem a todo momento prever e ter cautela quanto aos possíveis perigos ou uso indevidos dos resultados de seu trabalho.

Esses compromissos decorrentes da versão reformulada e atualizada do juramento de Hipócrates são apresentados de forma mais detalhada, por Popper, no artigo "La actitud crítica em Medicina: la necessidade de una nueva Ética" através de um decálogo, que ele considera como sendo sua proposta de uma nova ética profissional para os médicos. Os princípios que compõem esse decálogo são os seguintes (POPPER, 2014):

1. Não há autoridades, pois o conhecimento atual (que na perspectiva popperiana é sempre conjectural) excede o que uma pessoa pode conhecer, inclusive em sua própria especialidade. Esse conhecimento muda rapidamente e de forma radical. No geral esse avanço do conhecimento se dá por meio de correções de teorias e ideias equivocadas. Deste modo, haverá cientistas e médicos melhores ou piores. E o melhor cientista e o melhor médico é aquele que tem consciência de suas limitações.

2. Todos os seres humanos são falíveis, por isto é impossível se evitar todos os erros, mesmo aqueles que presumimos que podem ser evitados. Assim, a velha ideia de que é possível se evitar os erros é incorreta e precisa ser revista, pois conduz a hipocrisia e a desonestidade intelectual.

3. No entanto, continua sendo tarefa de todos os cientista e médicos fazer o possível para se precaver com relação aos erros. Mas, para realizar essa tarefa é preciso reconhecer o quão ela é difícil. Trata-se de um dever que ninguém é bem sucedido em realizá-lo. E, nem mesmo o grande cientista criativo, que segue suas intuições, está isento de erros, pois sua intuição pode lhe enganar.

4. É responsabilidade profissional do cientista e do próprio médico buscar os erros. Os erros se apresentam até mesmo em teorias bem testadas e corroboradas. Então, é dever do cientista ser tolerante com ideias novas que diferem dessas teorias já estabelecidas e não deve esperar que elas apresentem problemas para aceitar outras possibilidades. A descoberta de que uma teoria corroborada ou que um procedimento utilizado apresenta certas dificuldades ou erros é importante para o avanço da ciência.

5. O cientista ou o médico deve mudar sua atitude face aos erros. É justamente, neste aspecto que eles devem começar a reforma ética. Pois, a antiga ética os levava a ocultar os erros e a esquecê-los, o que deve ser visto como uma atitude antiética. A nova atitude, que denota uma postura ética, requer que reconheçam os erros.

6. O novo princípio ético é que os cientistas e médicos devem aprender com os erros, de modo que possam a vir a se precaver com relação a eles no futuro. Alguns erros acabam sendo conhecidos quando, por exemplo, um médico faz a amputação de um membro são ou um diagnóstico errado. E embora em alguns casos, o dano possa ser irreversível, o conhecimento desses erros pode possibilitar o debate e a análise dos mesmos, assim como, a adoção de novas práticas que visem preveni-los.

7. É dever do cientista e do médico ser autocrítico. Trata-se de manter uma atitude vigilante e crítica face aos erros, o que implica em dizer, que eles devem buscá-los e manter uma investigação completa acerca deles. 
8. Deve-se aceitar com dignidade e gratidão a critica de outros, pois é necessária e valiosa, na medida em que procura chamar a atenção para certos erros cometidos.

9. Deve-se ter sempre presente os erros similares que se cometeu ao apontar os erros dos outros. A crítica deve ser recíproca, mas ao fazê-lo é importante que se considere que errar é humano e que até mesmo os grandes cientistas cometeram erros.

10. A crítica racional deve ser direcionada aos erros que foram, claramente, identificados e não a pessoa que os cometeu. Deve estar fundada em razões, de modo a deixar claro o que esta sendo questionado e o porquê e, ser expressa de forma tal, que torne possível sua refutação. O seu objetivo deve ser a aproximação da verdade, por isto deve ser impessoal.

Essa nova ética, centrada na atitude critica face aos erros, tem como consequência uma maior consciência, por parte dos médicos, quanto aos seus erros, como também, implica na responsabilidade pelos mesmos e na busca de maneiras de reduzir a sua ocorrência, pois conforme acentuou Popper, a lealdade suprema dos médicos deve ser para com os doentes, pois são estes os mais prejudicados quando eles são mal sucedidos. E a melhor forma de reduzir os erros é registrá-los, analisá-los, discuti-los criticamente, com seus pares.

Para que essa ética, que requer a responsabilidade dos médicos face aos seus erros e a discussão critica dos mesmos, venha a ser bem sucedida, Popper propõe também, que a atuação médica deveria passar por processos de inspeção e revisão critica dos pares de modo a se ter um maior controle da validade dos diagnósticos e dos tratamentos prescritos aos pacientes e deste modo melhorar a qualidade do trabalho médico (POPPER, 2014). Pois, o problema ético de se melhorar os cuidados com o paciente é de responsabilidade de todos os médicos.

Mas, na supervisão do trabalho médico faz-se necessário, além da nova atitude face ao erro, um novo ethos, a tolerância. Esta resulta do reconhecimento da falibilidade humana, da consciência de que todos nós somos passiveis de erros, das próprias limitações de nossos conhecimentos, o que nos torna ignorantes sobre certos assuntos (POPPER, 1987a). Nesse sentido, não se deve aviltar a imagem do médico pelos erros cometidos, nem tampouco, imputar-lhe qualquer condenação decorrente da inspeção dos pares, pois se esta tiver esse propósito será eticamente condenável e desencorajará os médicos a participarem dela. A questão da supervisão deve ser vista da perspectiva educativa, não jurídica. Conforme esclarece Popper: "A tarefa deve ser educativa e prática: deve estar relacionada ao aperfeiçoamento de todos os médicos e não a condenação daqueles que cometem erros" (POPPER, 2014).

Assim, somente com um ethos dessa natureza seria possível se estabelecer um novo tipo de confiança entre os médicos, alicerçada na ideia de que a critica mútua não tem caráter pessoal ou pejorativo, mas sim que é fruto do respeito mútuo e do desejo de melhorar a saúde dos pacientes. Esta nova perspectiva tem como consequências uma maior valorização dos erros, não somente no sentido de identificá-los, como também, de buscá-los para que sejam, tão logo, corrigidos, quando for viável fazê-lo. Deste modo, é possível se aprender com os erros como também, que outros venham a aprender com eles. Quando esses erros ocorrem por falta de habilidade, os esforços devem ser no sentido de melhorá-la. Mas, quando resultam, como ocorre algumas vezes na medicina, por falta de atenção ou porque o médico deixou de fazer o que deveria ser feito, então, ele deve buscar maneiras de melhorar sua conduta de modo a evitá-los.

\section{Considerações finais}

A proposta popperiana de uma nova ética para a medicina se fundamenta na ideia de que o conhecimento científico não é um saber seguro e certo, mas sim que é falível e sujeito a erros. Nesse sentido, considera que na ciência não há certezas, como também, não há autoridades. A tarefa da atividade científica é combater os erros para que o conhecimento avance, para tal deve procurar identificá-los e eliminá-los. Nessa tarefa a meta é a verdade, mas o cientista deve ter sempre consciência do caráter conjectural de sua teoria e que para que ela seja considerada como verdade objetiva, mesmo que provisória, deve ser submetida ao crivo da crítica, 
principalmente, a de seus pares, ou seja, a crítica intersubjetiva da comunidade especializada. Essa crítica possibilita que percebam os erros e fraquezas de sua teoria como também, das dos outros. Assim, tendo por padrão a verdade e a crítica, os cientistas podem aprender com os seus erros, como também, podem descobrir as limitações dos conhecimentos que possuem, ou seja, o quão pouco sabem e o quanto há para saber.

Uma ética alicerçada em uma tal concepção de ciência, que valoriza o erro para o avanço do conhecimento, possibilita que os médicos vejam a si mesmos e o exercício de suas práticas de forma diferente. Em primeiro lugar, que não são autoridades, dada a limitação dos seus próprios conhecimentos face o progresso galopante da ciência. Em segundo lugar, que são seres falíveis e sujeitos a erros. Então, a atitude ética a ser cultivada é admitir os erros, se responsabilizar por eles e buscar formas de combatê-los, ao invés de tentar ocultá-los. O caminho indicado por Popper para enfrentar os erros é o diálogo, a discussão critica e o trabalho em equipe. Nesse sentido, os médicos devem dialogar com seus pares, debater suas dúvidas e erros. E também, compreender que com a discussão critica, eles poderão avançar e chegar a resultados mais precisos e se precaver com relação a erros futuros.

A proposta de uma ética que dá relevância ao erro mostra-se bastante atual, se consideramos os dados levantados por Fioravanti, em sua pesquisa sobre erro médico no Brasil, na qual aponta que de quase vinte milhões de pessoas que buscam tratamento em hospitais brasileiros, cerca de um milhão sofre as consequências de erros médicos, no decorrer do tratamento (FIORAVANTI, 2020). Muito embora seja uma preocupação mundial a redução dos danos provocados por erros médicos, em muitos países, como o Brasil, não se cultiva uma cultura que valorize a divulgação desses erros e a necessidade de se assumir a responsabilidade por eles. Esse assunto é, raramente, discutido no decorrer da formação dos médicos (MENDONÇA; GALLAGHER; OLIVEIRA, 2019). Assim, ao invés de se pensar medidas para se evitar os erros, procura-se estigmatizá-los e julgá-los. A questão do erro médico e sua responsabilização tem sido tratada, na maioria dos casos, de forma jurídica (BRAGA, 2018) e não de forma educativa, conforme propõe Popper.

Consideramos que as sociedades médicas, as equipes médicas dos hospitais e os próprios Conselhos de medicina devem fomentar os debates e a crítica acerca dos erros médicos, de modo que possam se acautelar com relação aos mesmos e não venham a repeti-los. Devem ter sempre consciência que esses erros resultam da falibilidade humana e que por isso devem ser tolerantes com os erros cometidos, mas a tolerância não significa acobertá-los ou ocultá-los, atitude que denota uma certa desonestidade intelectual, e sim reconhecerem, mutuamente, suas fraquezas e limitações e procurar corrigi-las. Então, a atitude a ser tomada com relação aos erros deve ser educativa no sentido de identificá-los e discuti-los, de modo a se prevenirem quanto a ocorrência de erros futuros.

Entendemos que esses debates não devem se restringir aos erros cometidos, devem envolver também, outros temas que estão relacionados ao cuidado com o paciente, como: os tratamentos duvidosos; a prescrição de novos medicamentos para as enfermidades, que surgem a cada dia, principalmente, aqueles cuja eficácia há controvérsias; os protocolos e procedimentos a serem adotados; os diagnósticos mais complexos, que são vistos, muitas vezes, pelo paciente como uma sentença de morte. É importante que esses temas sejam discutidos para que a decisão de prescrever um novo medicamento ou adotar um certo procedimento, não venha a recair apenas nas mãos de um único médico, que sozinho, em nome de sua autoridade e de uma suposta autonomia se considere com o direito de fazê-lo, muitas vezes contrariando até os próprios avanços da ciência. Em outras palavras, a adoção de novos tratamentos e/ou procedimentos, deve passar pela critica intersubjetiva da comunidade especializada, que com base em uma análise criteriosa, que observe, rigorosamente, os procedimentos metodológicos, decida sobre a eficácia do mesmo para o restabelecimento da saúde do doente. Pois, o que está em jogo nestas decisões é o cuidado com a saúde e a preservação da vida de um ser humano, e este deve ser o valor maior que deve nortear as decisões médicas. 


\section{Referências Bibliográficas:}

ARISTÓTELES. Metafísica. Tradução de Giovanne Rale. São Paulo: Edições Loyola, 2002.

BRAGA, I. de F. A. et al. "Responsabilização penal do médico no Tribunal de Justiça do Estado de São Paulo". In Einstein. v.16, n.1, p. 01-05, 2018. Disponível em https://journal.einstein.br/pt-br/article/responsabilizacao-penal-do-medico-no-tribunal-de-justica-do-estado-de-sao-paulo/ . Acesso em 10/03/2021

CORTINA, A. Ética aplicada e democracia radical. Madrid: Editorial Tecnos, 2008

CRAVEN-BARTLE, J. “Contribución de Popper a la ética médica: como aprender de los errores”. In Bioètica \&debat. Tribuna aberta del Institut Borja de bioètica. Año IX, n. 34, p. 01-05, 2003. Disponível em:

https://www.researchgate.net/publication/28212037 Contribucion de Popper a la etica medica como aprender de los errores. Acesso em 01/02/2021

DIAS, E.A. "Ciência e Ética em Popper: A ética da responsabilidade dos cientistas". In Revista Trans/Form/Ação, Marília, vol.44, no 03, p. 81-100, 2021. Disponível em https://revistas.marilia.unesp.br/index.php/transformacao/article/ view/10988. Acesso em 25/09/2021.

FERRIOL, A. M. "Ética médica como ética aplicada em perspectiva popperiana". In XVI Congrés Valencia de Filosofia. Valencia, Facultat de Filosofia i Ciéncies de l'Educación 6,7 i 8 d'abril de 2006. Valencia: Universitat de Valencia, p.179189, 2006. Disponível em: http://roderic.uv.es/handle/10550/46973. Acesso em 25/02/2021.

FIORAVANTI, C. "Um diagnóstico do erro médico". Revista Pesquisa/FAPESPA, janeiro/ 2021. Disponível em: https:// revistapesquisa.fapesp.br/um-diagnostico-do-erro-medico/. Acesso em 04/03/2021.

GOROWITZ, S.; MACINTYRE, A. “Toward a theory of medical fallibility”. In Journal of Medicine and Philosophy, vol. 01, p. 51-71, 1976. Disponível em: https://academic.oup.com/jmp/article/1/1/51/887444. Acesso em 01/02/2021.

JONAS, H. O Princípio Responsabilidade: ensaios de uma ética para a civilização tecnológica. Tradução de Marijane Lisboa e de Luiz Barros Montez. Rio de Janeiro: Contraponto/Editora PUC- Rio, 2006.

JONAS, H. Técnica, medicina e ética: sobre a prática do princípio responsabilidade. Tradução do Grupo da ANPOF. São Paulo: Editora Paulus, 2013.

LEMOS, N. "O monte Olimpo e os médicos que lá habitam". Jornal O Estadão, em 27/01/2021. Disponível em: https://politica.estadao.com.br/blogs/fausto-macedo/o-monte-olimpo-e-os-medicos-que-la-habitam/ . Acesso em 03/03/2021.

MENDONCA, V. S.; GALLAGHER, T. H.; DE OLIVEIRA, R.A. "The Function of Disclosing Medical Errors: New Cultural Challenges for Physicians". HEC Forum. v. 31, no 03, p. 167-175, setembro/2019. Disponível em : https://www. ncbi.nlm.nih.gov/pubmed/30178165. Acesso em 15/03/2021.

NEVES, N. C. Ética para os futuros médicos. É possível ensinar?. Brasília: Conselho Federal de Medicina, 2006

POPPER, K. A lógica da pesquisa científica. Trad. de Leonidas Hegenber. 2a edição. São Paulo: Ed. Cultrix, 1972.

POPPER, K. A sociedade aberta e seus inimigos. Trad. de Milton Amado. Belo Horizonte: Ed. Itatiaia; São Paulo: Ed. da Universidade de São Paulo, 1974a, vol. 1

POPPER, K. A sociedade aberta e seus inimigos. Trad. de Milton Amado. Belo Horizonte: Ed. Itatiaia; São Paulo: Ed. da Universidade de São Paulo, 1974b, vol. 2

POPPER, K. Conjecturas e refutações. Trad. de Sérgio Bath. $2^{\mathrm{a}}$ edição. Brasília: Editora da Universidade de Brasília, 1982.

POPPER, K. “Tolerância e responsabilidade intelectual”. In POPPER, K. Sociedade aberta Universo aberto. Trad. de Maria Helena Rodrigues de Carvalho. 1ª edição. Lisboa: Publicações Dom Quixote, 1987a, p. 93-110.

POPPER, K. O realismo e o objectivo da ciência. Trad. de Nuno Ferreira da Fonseca. $1^{\text {a }}$ edição. Lisboa: Publicações Dom Quixote, 1987b.

POPPER, K. "La actitud crítica em medicina. La necessid de uma nueva ética (1983)". In POPPER, K. Depués de la sociedade aberta: escritos sociales y políticos escogidos. Edición a cargo de Jeremy Shearmur y Piers Norris Turner. Trad. de Ferran Meler-Ortí. Barcelona: Paidós, 2014, p.420-435

POPPER, K. "A responsabilidade moral do cientista”. In POPPER, K. O mito do contexto. Trad. de Paula Taipas. Lisboa: edições 70, p. 153-161, 1999. 
RAMOS FILHO; C. F. ET AL. "Autonomia do médico deve respeitar a ciência”. Jornal Folha de São Paulo, em 30/01/2021. Disponível em: https://www1.folha.uol.com.br/opiniao/2021/01/autonomia-do-medico-deve-respeitar-a-ciencia.sht$\underline{\mathrm{ml} \text {. Acesso em 03/03/2021. }}$.

RIBEIRO, M. "O Conselho Federal de Medicina e a covid-19”. Jornal A Folha de São Paulo em 25/01/2021. Disponível em: https://portal.cfm.org.br/noticias/folha-de-s-paulo-publica-artigo-do-presidente-do-cfm-sobre-covid-19/ . Acesso em 02/03/2021

TESSLER, L e TÓFOLI, L. F. “O Conselho Federal de Medicina precisa respeitar a ciência”. Cultura e sociedade/ Notícias/ UNICAMP, em 28/01/2021. Disponível em: https://www.unicamp.br/unicamp/noticias/2021/01/28/o-conselho-federal-de-medicina-precisa-respeitar-ciencia . Acesso em 03/03/2021. 